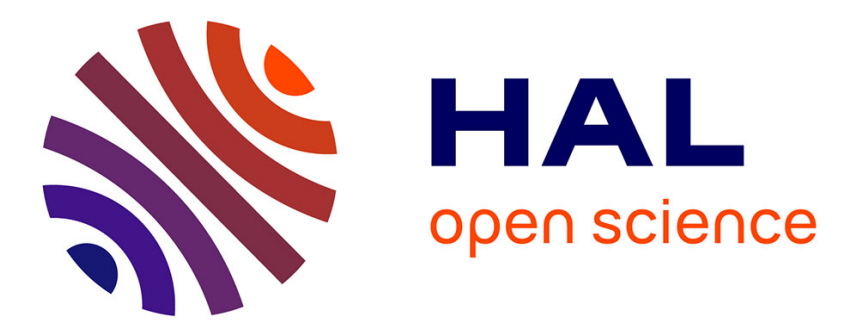

\title{
Viscosity measurements in a solution undergoing inverse melting
}

Roberta Angelini, Giancarlo Ruocco

\section{To cite this version:}

Roberta Angelini, Giancarlo Ruocco. Viscosity measurements in a solution undergoing inverse melting. Philosophical Magazine, 2007, 87 (3-5), pp.553-558. 10.1080/14786430600920839 • hal-00513755

\section{HAL Id: hal-00513755 \\ https://hal.science/hal-00513755}

Submitted on 1 Sep 2010

HAL is a multi-disciplinary open access archive for the deposit and dissemination of scientific research documents, whether they are published or not. The documents may come from teaching and research institutions in France or abroad, or from public or private research centers.
L'archive ouverte pluridisciplinaire HAL, est destinée au dépôt et à la diffusion de documents scientifiques de niveau recherche, publiés ou non, émanant des établissements d'enseignement et de recherche français ou étrangers, des laboratoires publics ou privés. 


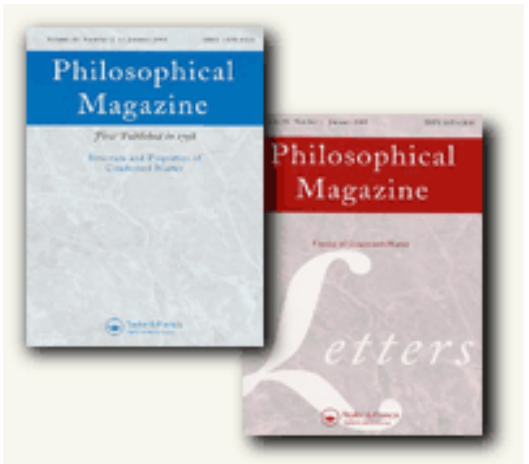

\section{Viscosity measurements in a solution undergoing inverse melting}

\begin{tabular}{|r|l|}
\hline Journal: & Philosophical Magazine \& Philosophical Magazine Letters \\
\hline Manuscript ID: & TPHM-06-May-0172.R2 \\
\hline Journal Selection: & Philosophical Magazine \\
\hline Date Submitted by the \\
Author: & 18-Jul-2006 \\
\hline Complete List of Authors: & $\begin{array}{l}\text { Angelini, Roberta; Universita "La Sapienza", Physics } \\
\text { Ruocco, Giancarlo; Universita "La Sapienza", Physics }\end{array}$ \\
\hline Keywords: & liquids, phase transitions, rheology, viscosity \\
\hline Keywords (user supplied): & inverse melting \\
\hline &
\end{tabular}

\section{S ScholarONE" \\ Manuscript Central}




\title{
Viscosity measurements in a solution undergoing inverse melting
}

\author{
R. Angelini and G. Ruocco
}

10

INFM CRS-SOFT and Dipartimento di Fisica, Università di Roma "La Sapienza" I-00185, Roma, Italy.

*corresponding author:

Email: roberta.angelini@phys.uniromal.it-Tel-Fax:+39075 5852767 


\section{$\S 1$ Introduction}

Great interest has been devoted in recent years to the phenomena of inverse melting and inverse freezing [1-3]. The first happens when a liquid heated at constant pressure undergoes a reversible liquid- to-crystal transition. Such a transition of endothermic nature implies the passage from a lowtemperature liquid to a high-temperature crystal with absorption of heat. This phenomenology is the opposite to what is usually expected for common liquids and indicates the presence of a crystal with entropy higher than its liquid counterpart. The inverse melting phenomenon has been recently studied via theoretical models [4-8]. A statistical-mechanical approach, which identifies two types of inverse melting, is reported in [7]. Spin models for inverse melting and inverse freezing in spin glasses are presented in [4-6]. In these models an inverse transition is found in the temperature (T) crystal field (D) phase diagram when the degeneracy of the interacting sites $(S= \pm 1)$ is higher than that of the holes $(S=0)$. A spin model suitable to study inverse freezing in fragile glass-forming liquids is reported in [8], here besides an inverse glass transition, at high values of D a fluid-fluid phase transition is observed between two paramagnetic phases. Inverse transitions rare to be found in common materials, have been experimentally detected in a polymer $[9,10]$, in ultrathin Fe films [11], in some metallic alloys [12] but a more extended list on the literature concerning examples of inverse melting and inverse freezing is reported in reference [5]. A new liquid system showing this kind of phenomenology has been recently found and investigated with quasielastic and elastic neutron scattering [13]; it is a solution of $\alpha$-cyclodextrin $(\alpha-C D)\left(\mathrm{C}_{36} \mathrm{H}_{60} \mathrm{O}_{30}\right)$, water and 4-methylpiridyne (4MP) $\left(\mathrm{C}_{6} \mathrm{H}_{7} \mathrm{~N}\right)$. This system has the advantage of showing inverse melting at normal pressure and in a temperature range easily achieved experimentally. These favourable thermodynamic conditions make it an advantageous system to investigate.

Here we present rheological measurements on such solutions and compare the obtained results with existent neutron scattering [13] and differential scanning calorimetric (DSC) [14] data. 


\section{§ 2. Experimental details}

4MP of $98 \%$ purity and $\alpha$-CD hydrate were purchased from Aldrich. The sample was prepared by mixing $\alpha-C D, 4 \mathrm{MP}$ and deionized water in the proper molar ratio through a magnetic stirrer for a time varying between one and three hours until a transparent solution was obtained. The sample soobtained was loaded in a rheometer RheoStress RS150 Haake using a stainless-steel couette geometry cell. The instrument is equipped with a sensor with coaxial-cylinder geometry (model Z20DIN ) which is its core. The solution was put in the two-cylinder system, of which the external one was thermalized with a cooling system composed of a liquid flux cryostat (DC50-K75 Haake) and the internal one, the sensor, was fixed to a rotor motor. During the experiment the instrument was used in an oscillatory mode and in a controlled stress (CS) configuration.

The measurements were performed at a frequency $\omega$ of $1.26 \mathrm{rad} / \mathrm{s}(v=0.2 \mathrm{~Hz})$ in the temperature range $293 \mathrm{~K}-363 \mathrm{~K}$. Samples were prepared at five different concentrations of $\alpha \mathrm{CD}$, water and 4MP with molar ratios of 1:6: $x$ with $40<x<90$, the concentration of the solution being varied by changing the quantity of $4 \mathrm{MP}$.

The dynamical complex viscosity $\eta^{*}$, the storage modulus $G^{\prime}$ and the loss modulus $G^{\prime \prime}$, related through the relation $G^{*}=G^{\prime}+i G^{\prime \prime}=i \omega \eta^{*}$, have been measured as a function of the temperature. An example of the measured curves is reported in Fig. 1 where the viscosity is plotted on a logarithm scale as a function of the temperature.

[Insert figure 1 about here]

\section{§ 3. Results and discussion}

Viscosity measurements as a function of temperature at different concentrations have been performed at a heating rate of $0.6 \mathrm{~K} / \mathrm{min}$ from room temperature up to a maximum of $360 \mathrm{~K}$. For each investigated concentration, starting from values of $\left|\eta^{*}\right| \sim 10^{-2} \mathrm{~Pa} \cdot \mathrm{s}$, an abrupt increase of several order of magnitude in the viscosity, up to values typical of the instrumental limit, is observed. It happens at temperatures that depend on the specific concentration. This behaviour indicates the presence of a phase transition during which the system passes from a liquid to a solid phase. The crystalline nature of this phase has been discussed in reference [13]. A fit with a sigmoidal function has been performed to extract the transition temperature whose uncertainty has been calculated through the semi-dispersion between two temperature values just below and just above the transition. 
The transition temperature is plotted as a function of the concentration in Fig. 2 (full triangles).

\section{[Insert figure 2 about here]}

It is evident that the temperature at which the transition takes place decreases with increasing concentration of $\alpha \mathrm{CD}$. The viscosity measurements have been compared with existing quasielastic and elastic neutron scattering data [13] (open circles) performed at a heating rate of $0.1 \mathrm{~K} / \mathrm{min}$ and with differential scanning calorimetric (DSC) data [14] (full squares) acquired at a heating rate of $10 \mathrm{~K} / \mathrm{min}$. As shown in Fig. 2 the three sets of data are compatible within the error bars at low concentrations of $\alpha \mathrm{CD}$ in $4 \mathrm{MP}$, while a non-negligible difference in the transition temperature detected with the viscosity measurements is observed at higher concentrations of $\alpha \mathrm{CD}$.

The reversibility of this transition, observed by the naked eye, has also been investigated performing a temperature scan at fixed concentration (1:6:90), first heating and then cooling the solution at a heating rate $r=1.7 \mathrm{~K} / \mathrm{min}$ as shown in Fig. 3 .

\section{[Insert figure 3 about here]}

It is evident from the jump in the viscosity curve that in the heating process the solution undergoes a liquid-solid transition with subsequent melting during the cooling down. The large difference between the liquid-solid and solid-liquid transition temperatures provides evidence for a clear thermal hysteresis. Similar results have been observed for the scattered intensity in quasielastic neutron scattering measurements [13] and for the heat flow in DSC experiments [15].

Viscosity measurements at three different heating rates $(0.2,0.6$ and $1.7 \mathrm{~K} / \mathrm{min})$ are reported in Fig. 4 for the concentration ratio 1:6:90. It indicates a shift of the transition temperature toward higher $T$ as the heating rate is increased.

[Insert figure 4 about here]

A similar study has been performed by Tombari et al. [15] through DSC measurements on a solution with concentrationratio 1:6:100 to determine the the heating-rate dependence of the transition temperatures associated with the liquid-solid transition. In particular, two types of transition temperatures have been reported: the peak temperature $\left(T_{\text {peak }}\right)$, which is the temperature position of the maximum of an endothermic peak and the onset temperature $\left(T_{\text {onset }}\right)$, which is the 


\section{1}

temperature obtained by the intersection between the tangent drawn at the point of greatest slope of an endothermic peak and the extrapolated baseline. A comparison between these DSC data and viscosity data on a sample at concentration ratio 1:6:90 has been done after a rescaling to take into account the different concentration values. The two sets of data reported in Fig. 5 show good agreement and a compatible trend.

[Insert figure 5 about here]

\section{§ 4. Conclusions}

In conclusion we have presented rheological measurements on a solution of $\alpha \mathrm{CD}$, water and 4MP. These components mixed in the proper molar ratio give rise to the phenomenon of inverse melting in a temperature range between $300 \mathrm{~K}$ and $340 \mathrm{~K}$, depending on the concentration. The extracted values for the liquid-solid transition temperature show good agreement with existing elastic and quasielastic neutron scattering and DSC measurements. The reversibility of such a transition, together with a pronounced thermal hysteresis, has been observed. Further measurements as a function of the heating rate show that the transition temperature is shifted towards higher $T$ at increasing heating rate. 


\section{References}

[1] F. H. Stillinger and P. G. Debenedetti, Biophys. Chem. 105, 211 (2003).

[2] A. Lindsay Greer, Nature 404, 134 (2000).

[3]. G. P. Johari, Phys. Chem. Chem. Phys. 3, 2483 (2001)

[4] A. Crisanti and L. Leuzzi, Phys. Rev. Lett. 95, 087201 (2005).

[5] N. Schupper and N. M. Shnerb, Phys. Rev. Lett. 72, 046107 (2005).

[6] N. Schupper and N. M. Shnerb, Phys. Rev. Lett., 93, 037202 (2004).

[7] M. R. Feeney, P. Debenedetti and F. H. Stillinger, J. Chem. Phys. 119, 4582 (2003).

[8] M. Sellitto, Phys. Rev. B, 73,1802026.

[9] S. Rastogi, G. W. H. Hohne and A. Keller, Macromolecules 32, 8897 (1999).

[10] S. Rastogi, M. Newman and A. Keller, Nature 353, 55 (1991).

[11] O. Portman, A. Vaterlaus and D. Pescia, Nature 422, 701 (2003).

[12] W. Sinkler, C. Michaelsen and R. Bormann, J. Magn. Res. 12, 1872 (1997).

[13] M. Plazanet, C. Floare, M. R. Johnson, R. Schweins and H. P. Trommsdroff, J. Chem. Phys. 121, 5031 (2004).

[14] R. Angelini, G. Ruocco, S. De Panfilis and F. Sette, 2006, unpublished

[15] E. Tombari, C. Ferrari, G. Salvetti and G.P. Johari, J. Chem. Phys. 123, 051104 (2005). 


\section{Figure captions}

Figure 1.

Complex viscosity of $\alpha \mathrm{CD}$-water-4MP solutions is shown as a function of the temperature on a logarithm scale for different concentrations at the indicated molar ratios measured in oscillatory mode at a frequency $\omega=1.26 \mathrm{rad} / \mathrm{s}$ and at heating rate $0.2 \mathrm{~K} / \mathrm{min}$ as discussed in the text.

Figure 2.

Liquid-solid transition temperature of $\alpha \mathrm{CD}$-water-4MP solutions as a function of the concentration. Triangles: rheometric measurements in oscillatory mode $(\omega=1.26 \mathrm{rad} / \mathrm{s})$ at a heating rate $r=0.6$ $\mathrm{K} / \mathrm{min}$; squares: DSC measurements at heating rate $r=10 \mathrm{~K} / \mathrm{m}$ [14]; circles: quasielastic and elastic neutron scattering measurements from reference [13] at heating rate $r=0.1 \mathrm{~K} / \mathrm{min}$.

Figure 3.

Hystersis loop of the complex viscosity of $\alpha \mathrm{CD}$-water-4MP solutions in logarithm scale at fixed concentration $(1: 6: 90)$ and at a heating rate $r=1.7 \mathrm{~K} / \mathrm{min}$.

Figure 4.

Complex viscosity of $\alpha \mathrm{CD}$-water-4MP solutions at the concentration 1:6:90 is reported on a logarithm scale as a function of the temperature for the three indicated heating rates.

Figure 5.

Liquid-solid transition temperature of $\alpha \mathrm{CD}$-water-4MP solutions as a function of the heating rate. Diamonds represent rheometric measurements in an oscillatory mode as described in text at the concentration ratio 1:6:90; open and full circles are respectively $T_{\text {onset }}$ and $T_{\text {peak }}$ from DSC measurements [15] at the concentration ratio 1:6:100 after rescaling. A linear fit on the rheometric data is also shown. 


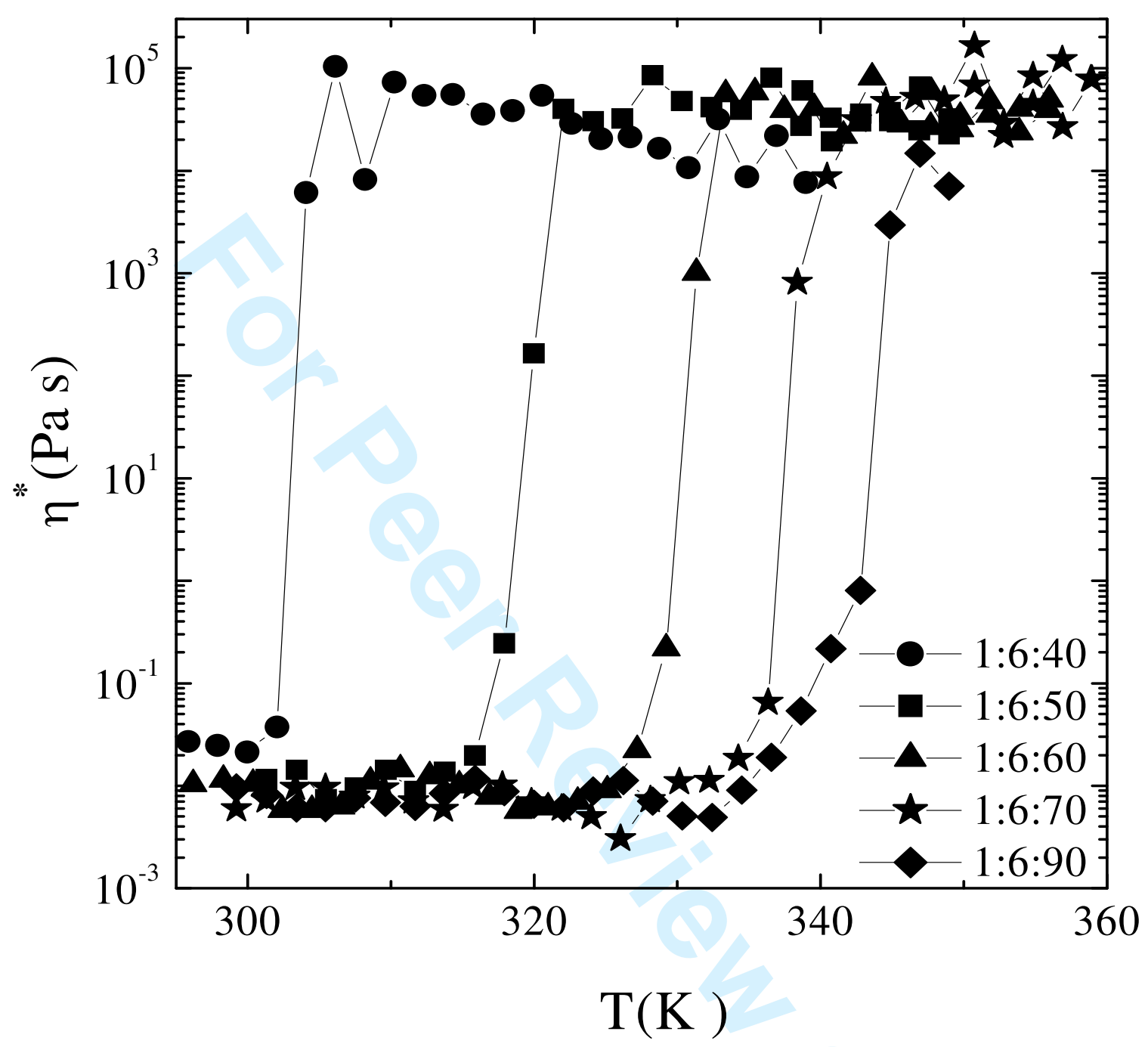

FIGURE 1 


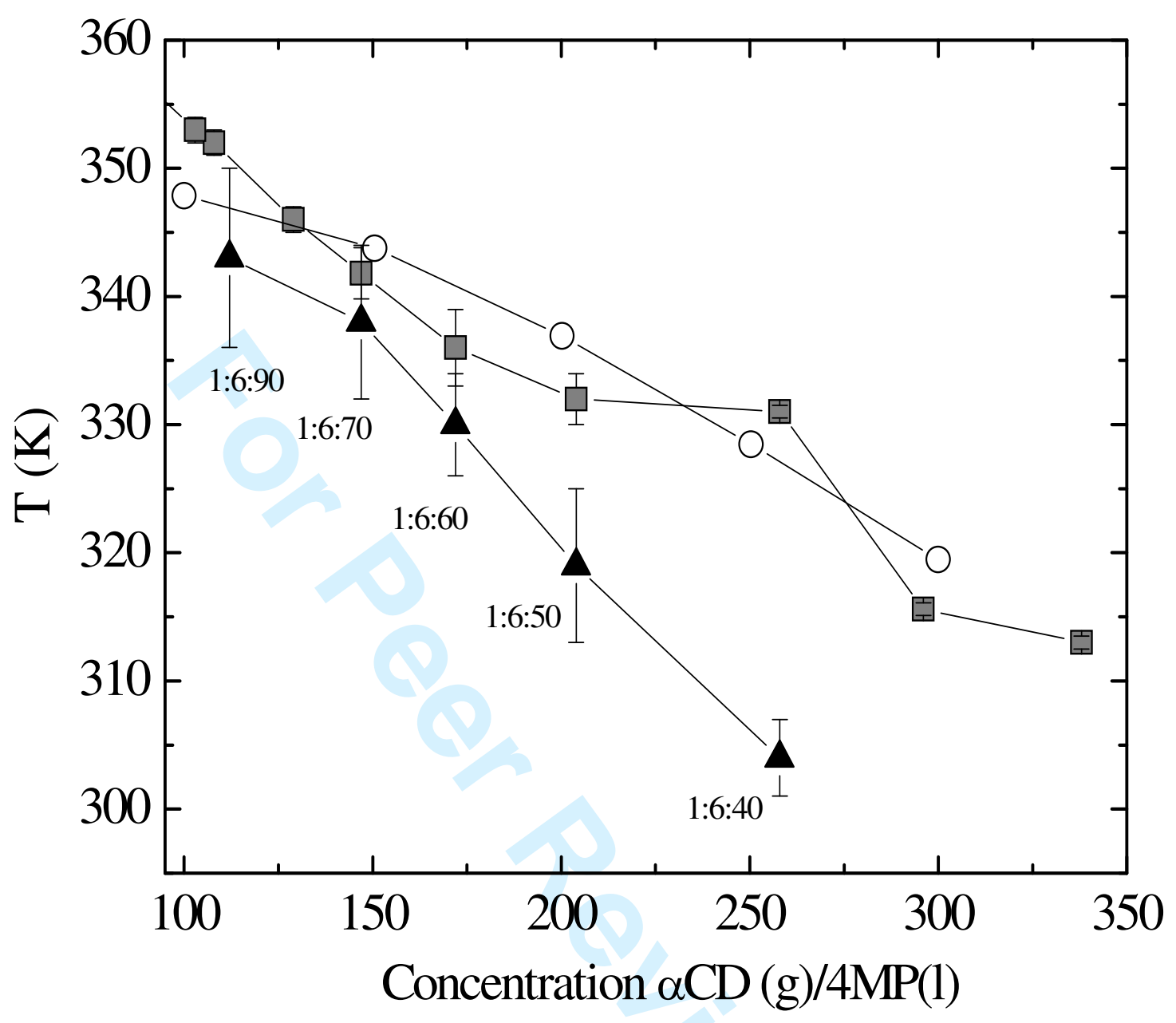

FIGURE 2 


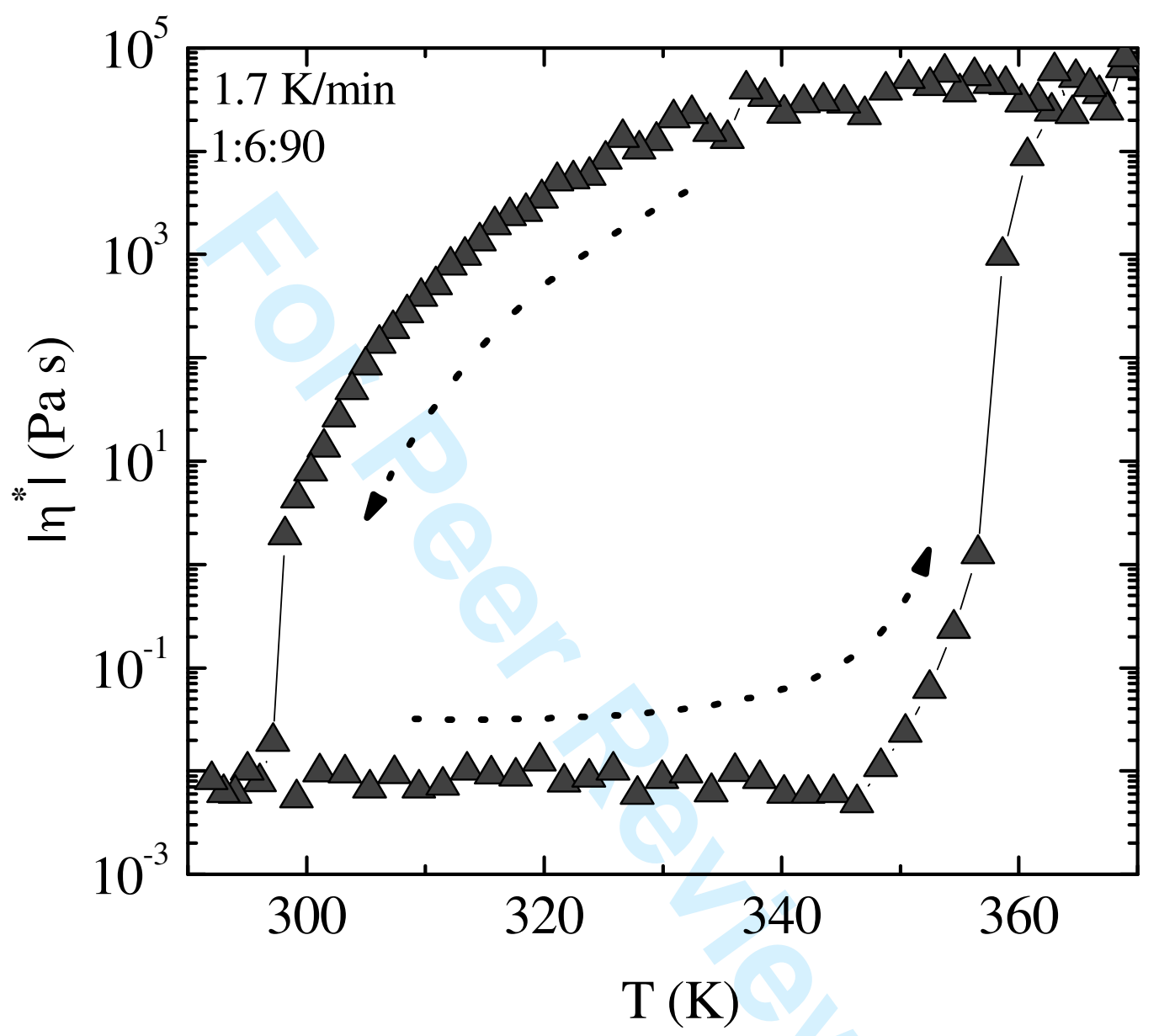

FIGURE 3 


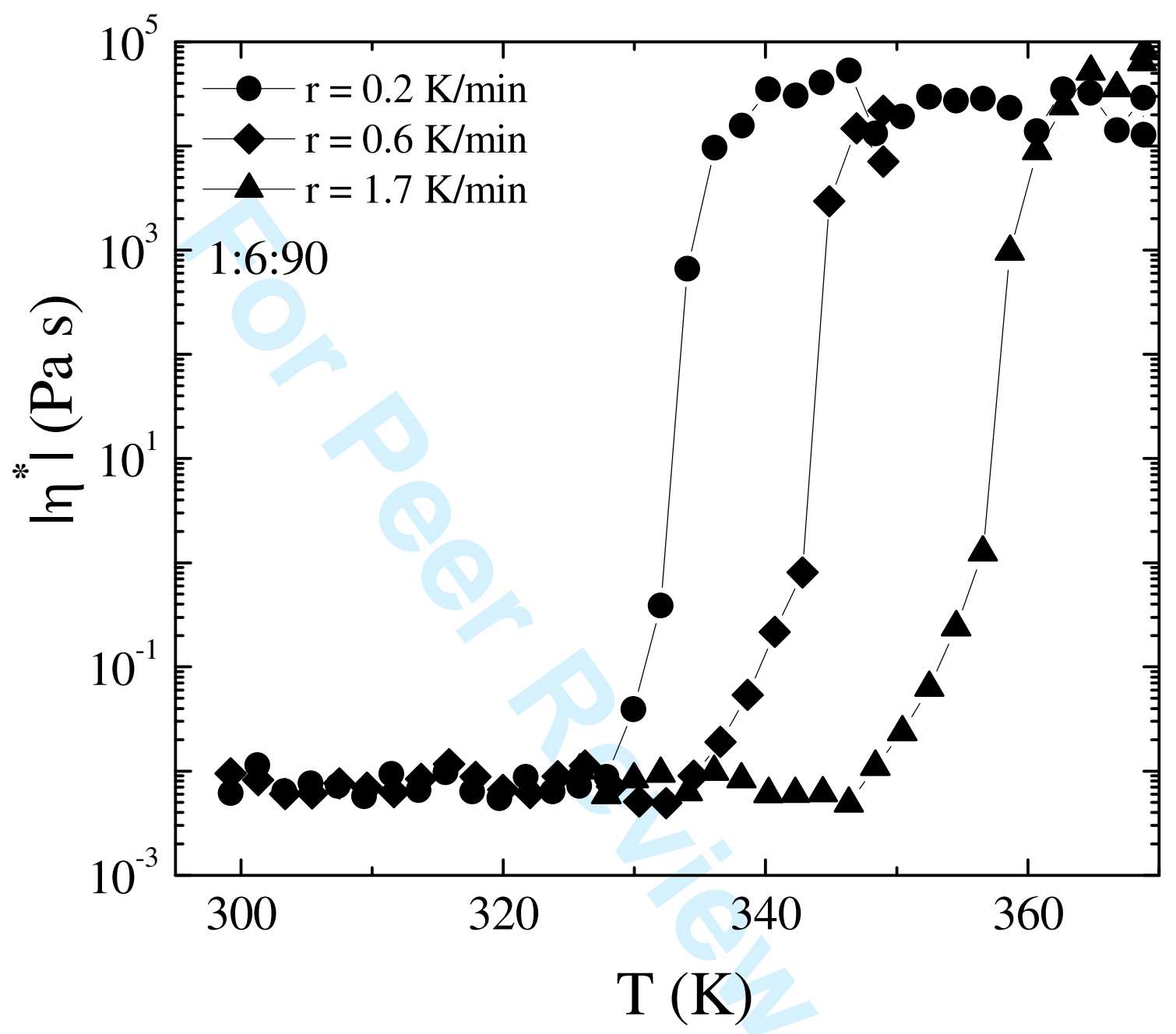




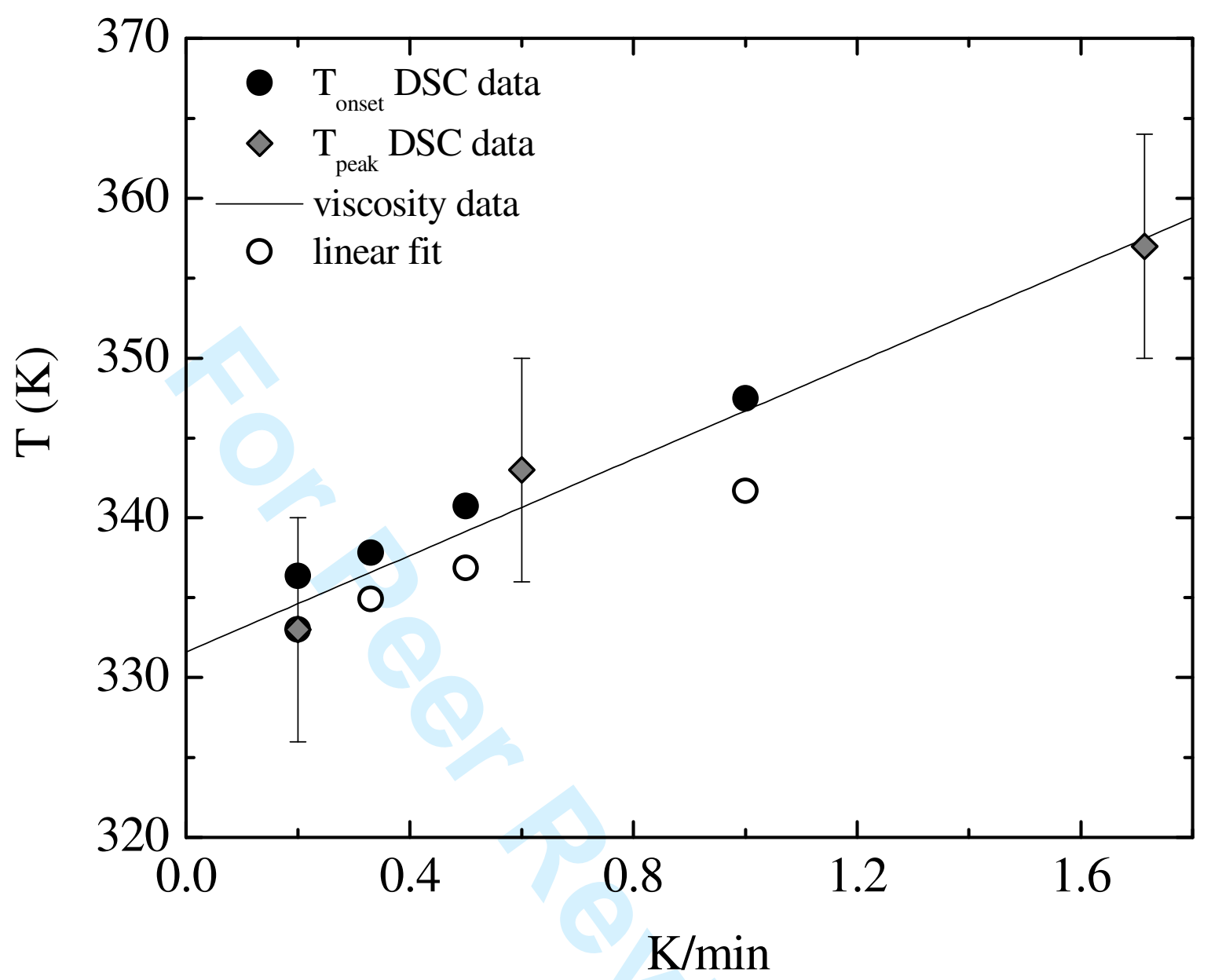


